\title{
God, lions, and Englishwomen
}

Book or Report Section

Accepted Version

Schroeder, S. (2018) God, lions, and Englishwomen. In: Gálvez, J. P. and Gaffal, M. (eds.) Human Understanding as Problem. Aporia (11). de Gruyter. ISBN 9783110611205 doi: https://doi.org/10.1515/9783110613384-011 Available at http://centaur.reading.ac.uk/75540/

It is advisable to refer to the publisher's version if you intend to cite from the work. See Guidance on citing.

To link to this article DOI: http://dx.doi.org/10.1515/9783110613384-011

Publisher: de Gruyter

All outputs in CentAUR are protected by Intellectual Property Rights law, including copyright law. Copyright and IPR is retained by the creators or other copyright holders. Terms and conditions for use of this material are defined in the End User Agreement.

www.reading.ac.uk/centaur 


\section{CentAUR}

Central Archive at the University of Reading

Reading's research outputs online 


\title{
God, Lions, and Englishwomen \\ Wittgenstein on Understanding People
}

\author{
Severin Schroeder (University of Reading)
}

Gott, wenn er in unsre Seelen geblickt hätte, bätte dort nicht sehen können, von wem wir
sprachen.

If God had looked into our minds he would not have been able to see there whom we were speaking of. [PPF \$284]

Wenn ein Löwe sprechen könnte, wir könnten ihn nicht verstehen.

If a lion could talk we wouldn't be able to understand it. [PPF \$327]

Es ist für unsre Betrachtung wichtig, daß es Menschen gibt, von denen jemand fühlt, er werde nie wissen, was in ibnen vorgeht. Er werde sie nie verstehen. (Engländerinnen für Europäer.)

It is important for our approach, that someone may feel concerning certain people that he will never know what goes on inside them. He will never understand them. (Englishwomen for Europeans.) [CV 84 (MS 137, 71; 9.7.1948)]

\section{The Inner-Object Conception}

The concept of understanding occurs in Wittgenstein's writings first and mainly with respect to language. Understanding is discussed as a correlative to meaning and explanation. Wittgenstein argues against the idea of understanding as an inner process or occurrence: a mental representation of what is understood. Locke presented the view that words have meaning if they are accompanied by a mental image in the mind of him that uses them' (Locke 1690, 3.2.2). Understanding would then require that the same words are associated with the same images in the mind of the hearer. A little reflection shows, however, that what comes before our minds when we understand a word - a picture, or mental image — cannot determine or constitute our understanding of the word; for the same mental image can accompany the hearing of a word in two people when they understand the word very differently $(P I \$ 140)$. They may, for example, both 
imagine an Alsatian, when one of them takes the word in question to mean 'dog', while the other understands it to mean 'Alsatian'. Similarly, the same mental image can accompany our understanding of completely different words, which we know to be different in meaning: thus the word 'winter' may make me see the image of a snow covered street, but the same image may come up in my mind when I hear the words 'snow' or 'Advent'. On the other hand, very often when I use or understand the word 'winter' no such mental imagery occurs (cf. PI \449). Mental images are neither a sufficient nor a necessary condition of understanding.

Conceding that our words are not always accompanied by mental images, one may still be inclined to insist that understanding must consist in some sort of mental representation, whatever it may be. When I understand that something is the case, it would appear that the object of my understanding must somehow be represented in my mind. And the same applies to other intentional states: what I remember, intend, desire, or fear must, surely, be represented in my mind when I have that memory, intention, desire, or fear - at least while I am conscious of it. Not so. To show that this natural assumption of some form of mental representation is just a prejudice, Wittgenstein invites us to consider cases of instantaneous understanding (or remembering, intending, etc.) 一:

A writes series of numbers down: B watches him and tries to find a law for the sequence of numbers. When he succeeds he exclaims: "Now I can go on!" - So this capacity, this understanding, is something that makes its appearance in a moment. [PI\$151]

I want to remember a tune and it escapes me; suddenly I say "Now I know it" and sing it. What was it like to suddenly know it? Surely it can't have occurred to me in its entirety in that moment! — Perhaps you will say: "It's a particular feeling, as if it were there" [PI \$184]

There is no doubt that I now want to play chess, but chess is the game it is in virtue of all its rules (and so on). Don't I know, then, which game I want to play until I have played it? or are all the rules contained in my act of intending? [PI \$197]

This is what I call the paradox of the instantaneous experience of complex contents: The contents must all be there in a flash, for I can correctly avow that at a particular moment I have understood, intend, expect or remember. But then again, the contents are not all there in a flash, for I am not really aware of all the details: all possible uses of the word; all numbers of an arithmetic series; all notes of a melody; all rules of chess; they are not all in front of my mind at the same time. That is particularly obvious in the 
case of understanding an arithmetical series, where the object of understanding is literally infinite.

Understanding is a capacity, typically a long-term capacity. As such it is not something one is continuously conscious of. I understand some French and I understand how to play chess, but I am not continuously thinking of these abilities. There is no constant awareness of one's abilities. They are not enduring occurrences in one's consciousness. However, the first appearance of an understanding is often experienced as a sudden insight (when the penny drops). Wittgenstein gives this example: $B$ tries to understand the series of numbers $A$ is writing down: $1,5,11,19, \ldots$ Suddenly $B$ realises that the next number must be 29 (PI \$151). What, in this case, is the understanding? Different things may happen, none of which seem necessary or sufficient. In particular, saying the formula to oneself is not enough, since one may be given the formula and not know what to do with it $(P I \$ 152)$. So what more is required to make it an instance of understanding? Obviously, it is also required that one is in fact able to continue correctly. But how can one be so sure beforehand that having the formula in one's mind will enable one to continue correctly? Is it perhaps a matter of induction, that is, of reasoning from past experience: 'Whenever in such a situation a formula occurred to me I could correctly continue the series. Now a formula has occurred to me. So, I shall be able to continue correctly'? Not exactly. It may indeed be a matter of past experience, but not of reasoning from past experience. The utterance 'Now I can go on' is not the expression of such reasoning, nor would one offer such reasoning to justify one's confidence. On the other hand, one's past experience and proficiency in dealing with algebraic formulae may well be a cause of one's confidence on this occasion; and it may be a reason for others to trust one's confidence (PI $\left.\int \$ 179 ; 324\right)$. But as far as my current experience in such a situation is concerned, all I can say is that a formula has occurred to me and now I'm confident that I can go on. The important point to note is that my awareness of the formula does not imply an immediate awareness of all its applications. The applications are not contained in the formula.

The paradox of the immediate experience of complex, or even infinite, contents resulted from a mistaken, but very natural, idea of a mental process or occurrence. It is extremely tempting to envisage mental occurrences as comprehensive representations: that must somehow contain everything the mental representation is about or directed at. That kind of mental representation would be astonishing enough where what we have in mind is fairly complex - as with the rules of chess, which appear to be represented in 
our momentary desire to play chess (PI \$197); but it becomes patently impossible when we mean or understand an infinite arithmetical series. At first glance it may seem that such infinity could conveniently be represented by a short formula, but then it becomes clear that our meaning or understanding the formula would have to contain how the formula was to be applied in an infinity of instances (to forestall an infinity of possible misunderstandings) — which again, appears to make such meaning (or understanding) a mind-boggling feat. So, how can the mind perform such a feat? It cannot. The truth is that no such marvellously rich representation occurs; and it is an error to think that it needs to occur for meaning (or understanding) to be possible. That is the dissolution of the paradox of the immediate experience of complex, or even infinite, contents. Understanding is a capacity (or the acquisition of a capacity), which - contrary to a deep-seated philosophical prejudice — is not, indeed cannot be, accounted for in terms of mental representation. For whatever mental representation you might envisage, it would always need to be complemented by an understanding of how to interpret or apply it (PI $\left.\int § 139-40\right) .{ }^{1}$

\section{Understanding Others}

A corollary of the inner-object view of the mind is that the thinking and feeling of others are processes inside them, hidden from our view. This natural philosophical picture is reflected in various commonly used spatial metaphors that present understanding people as seeing what is inside their minds. That is the target of the first of three quotations, from which I derived my title:

If God had looked into our minds he would not have been able to see there whom we were speaking of. [PPF \284]

The claim here is not that God could not know whom we were speaking about — of course he could, he's omniscient. It is just that, in many cases, such knowledge could not be derived from an inspection of our mind: it could not be read off the words and images going through our minds when speaking. As explained before, the contents of what we think, intend or mean can never be comprehensively present in our consciousness.

\footnotetext{
${ }^{1}$ For a more detailed account of Wittgenstein's critique of the inner-object conception, see Schroeder 2006, 181-220.
} 
If I say "I meant him" very likely a picture comes to my mind, perhaps of how I looked at him, etc.; but the picture is only like an illustration to a story. From it alone it would mostly be impossible to conclude anything at all; only when one knows the story does one know the significance of the picture. [PI \$663]

This brings out the limit of the spatial metaphor of the inner realm. When somebody says something that you don't fully understand, because it is not very clearly expressed, perhaps ambiguous or very vague, and you ask for an explanation (What exactly do you mean?'), the answer will typically not be something that was already there, fully formulated but not said out loud, in the person's consciousness. Therefore, even a godlike look into the privacy of your interlocutor's consciousness would not give you the answer to your request for clarification.

Consider again the example of someone saying 'Let's play chess!' and suppose I have come across various regional versions of the game: small variations in some of the rules, and I wonder which one he meant. It is not only unlikely that while making his suggestion he mentally rehearsed all the rules to himself thus disambiguating which type of chess he meant, it is quite impossible: you cannot run through all the rules of chess in the three seconds it takes you to ask the question. So, again, my interlocutor will normally be able to say which version he meant, but it will not be a matter of just saying loudly what he had already said or visualised to himself quietly in foro interno.

\section{Reasons and Causes}

When it comes to understanding human behaviour — why somebody has done something — the inner-process account of the mind leads naturally to a causal construal of agential reasons. Understanding why he did it we are then inclined to construe as: what caused him to do it. And the causes we look for are, again, occurrences in the mind.

Wittgenstein emphatically rejects this view, arguing for a conceptual distinction between reasons and causes. A person's reason for acting is what he can honestly present to explain and justify his behaviour, which is very often not something he did say to himself before acting. Thus there's a categorial difference between a reason and a cause: while the latter is an occurrence, the former is not: it is the possible exercise of a capacity to explain. By looking into our minds and observing mental occurrences causing our behaviour, God would not see our reasons. 
However, having discussed this topic elsewhere (Schroeder 2017), I shall not pursue it further in this paper.

\section{Wittgenstein's Lion}

From the person who expresses a wish to play chess, without having a comprehensive representation of the game in his mind, we move to Wittgenstein's famous lion dictum:

If a lion could talk we wouldn’t be able to understand it. [PPF \$327]

This remark has been the object of much bewildered and controversial debate (cf. Sandis 2012); quite needlessly. For almost all the positions taken in this debate - even the views of distinguished Wittgenstein scholars - are due to the fact that people cannot resist the temptation of treating the sentence as an aphorism, that is, a saying that is to be interpreted on its own without any context. Such an aphoristic reading is taken to its extreme by Philippe de Lara who declares the lion sentence to be intentionally ambiguous: 'true, false and nonsensical', depending on which of the possible and equally licit interpretations one chooses (de Lara 2005, 135-7).

To begin with, Wittgenstein's remark has been taken to be an empirical claim about lions - and then criticised as uninformed by zoologists that find feline communications perfectly understandable (e.g. Bekoff 2000, 38). But as Constantine Sandis observes, Wittgenstein was as little interested in lions as Thomas Nagel was in bats (Sandis 2012,141). His concern was with the problem of understanding creatures we find alien. If a lion's behaviour is perfectly intelligible to you, think of (or imagine) some other kind of animal that you do find strange.

Gordon Baker and Peter Hacker interpret the 'initially mystifying' lion remark to mean that:

any 'form of life' accessible to lions, given their natural repertoire of behaviour and their behavioural dispositions, is too far removed from ours for any noises they might emit to count as speech [Baker \& Hacker 1985, 186; n.1].

Hence, any speaking lion we might imagine (e.g. in a fairy tale) 'is really a human being "in the shape of a lion"” (ibid.). Although the point is a plausible one, it is unlikely to be what Wittgenstein meant to convey by his remark. True, there is an inconsistency in the 
antecedent, but counterfactual conditionals are often to be taken with a pinch of salt (cf. Sandis 2012, 146). Indeed, we often say perfectly understandable things based on per impossibile conditions. Consider:

(1) If I were you, I would stop smoking.

To point out in response that there is an inconsistency in the idea of one person being another would be missing the point of this remark (which has nothing to do with the criteria of personal identity). And if, in a philosophical context, one wanted to make the point that two concepts are incompatible, it would be very misleading to combine them in the antecedent of an explicitly counterfactual conditional, unless the consequent was a patent and logically independent falsehood. Thus, one could perhaps convey the claim that time travel was logically impossible by saying:

(2) If you could travel backwards in time, you might just as well be a married bachelor.

But one could hardly hope to convey it by saying, for example:

(3) If you could travel backwards in time, you would not be able to reach the $18^{\text {th }}$ century.

A slightly different reading of the lion remark has been offered by Hanjo Glock:

On a charitable reading, it means that if lions had a feline language of complex growls, roars, etc., we could never come to learn it. Why? Because their form of life, and their behavioural repertoire, are so alien to us. [Glock 1996, 128]

However, the focus of the lion remark appears to be psychological, rather than linguistic understanding (cf. Sandis 2012, 148). Wittgenstein writes: 'we could not understand it/him [ibn]' (referring back to the lion), rather than 'we could not understand his language'. Moreover, attributing to the lion an incomprehensible and unlearnable language would contradict Wittgenstein's view that noises that we could not learn to understand we could not call a language (PI \$207).

In fact, Wittgenstein's concern in the lion remark is not with linguistic understanding, just as he is not particularly interested in zoological details, and his remark 
is not as mystifying as people think. The enigma is easily resolved, the point becomes quite clear, once we stop treating it as an aphorism and instead consider it in its context.

To begin with, an earlier version of the remark makes it clear what kind of difficulty of understanding Wittgenstein has in mind:

Wenn der Löwe sprechen könnte, wir könnten ibn nicht verstehen. Er wird uns durch ein gewisses Benehmen ein Rätsel, rätselhaft.

[MS 167, 12v-13r]

If a lion could speak, we would not be able to understand him. He becomes an enigma, enigmatic to us through a certain kind of behaviour.

That is to say, it is not the language that produces the enigma, but certain aspects of lions' behaviour that are very alien to us. Think, for example, of a male lion taking over a new pride and killing all male cubs. But as noted before, the zoological details are not Wittgenstein's concern. The lion is merely a randomly chosen example of an animal that struck Wittgenstein as rather alien: behaving very differently from humans and therefore difficult to understand.

Next, we apply to this case the philosophical picture of understanding that Wittgenstein is concerned to attack (which is under discussion in the passages surrounding the lion remark): the idea that understanding is seeing what is going on in somebody's mind. On this account, failure to understand somebody would mean: being unclear or ignorant about what is going on in their mind. Hence, failure to understand a lion would be due to our not being able to see what is going on in its mind: not being able to see the lion's thoughts underlying its behaviour. To attack that picture, Wittgenstein presents a little thought experiment. If what it takes to understand the lion is that the lion's inner thoughts get somehow expressed, let's assume that a lion could do so: by expressing its thoughts in words. In that manner: what's inside is brought out: made public. Now, with the contents of the lion's mind expressed in words, we should be able to understand it. But we don't! The externalisation, the making public and perceptible to us what is in the lion's consciousness would not make the lion's behaviour any less odd or enigmatic. (If, for example, you find it strange that a lion should kill all the male cubs sired by other males, it would hardly help your understanding to hear him say: 'Right, now I'm going to kill all the male cubs sired by my predecessor!')

That the lion remark is concerned not with language, but with the philosophical picture of understanding others as perceiving what's inside them is made perfectly clear 
by the elucidating continuation of the remark in MS 137 (published in Last Writings on the Philosophy of Psychology Vol.1):

190. If a lion could talk we could not understand him.

191. Even if someone were to express everything that is 'within him', we wouldn't necessarily understand him.

192. So he gets angry, when we see no reason for it; what excites us leaves him unmoved.-...

[MS 137, 96a-97b; LW I \§190-2]

Understanding somebody is not seeing what's going on in their minds. Thus the lion remark turns out to be just a variant of the God remark: There it was God entering someone's mind; here it is a lion expressing the contents of its mind. In neither case, seeing the inner provides understanding.

Moreover, in MS 137 the lion remark is preceded by a note in square brackets with a reference to another remark which it is meant to elucidate. Such, then, is the arrangement at the next stage of revision (in MS 144, the manuscript underlying the Typescript 227 that Elizabeth Anscombe published as Philosophical Investigations Part II): Wittgenstein introduces the lion remark by the following:

"I can't know what is going on in him" is above all a picture. It is the convincing expression of a conviction. It does not give the reasons for the conviction. They are not obvious.

[PPF』326]

This once more indicates the point of the lion remark: namely to put pressure on the philosophical picture of understanding others as seeing what is going on inside them. To put it like that is only a picture, a metaphor for not understanding, not an explanation of why we don't understand. It is comparable to saying that something you don't understand is 'a closed book to you'.

To summarise: it is not a speaking lion as such that is incomprehensible; rather an ordinary lion is Wittgenstein's example of a creature alien to us, and his point is that our understanding would not be helped if that lion could speak and thus lay open to us what's going on inside its mind.

2 The corresponding German idiom is even more picturesque: ein Buch mit sieben Siegeln (a book with seven seals). 


\section{Strange people (Englishwomen)}

Finally, before the remark just quoted from MS 144 Wittgenstein placed an extended version of the third of my thematic quotations (the one about Englishwomen):

We also say of a person that he is transparent to us. It is, however, important as regards our considerations that one human being can be a complete enigma to another. One learns this when one comes into a strange country with entirely strange traditions; and, what is more, even though one has mastered the country's language. One does not understand the people. (And not because of not knowing what they are saying to themselves.) We can't find our feet with them.

[PPF $₫ 325]$

The analogy with the lion remark (which follows a little further down the page) should now be obvious. Again, it concerns strange creatures we find incomprehensible (since, apparently, Wittgenstein felt at a loss to understand Englishwomen). Is this, as the philosophical picture under discussion suggests, because we don't know what is going on inside their minds: what they are saying to themselves in foro interno? No, as the parenthesis says explicitly: that is not the reason why such people are enigmatic to us. Even if, god-like, we could eavesdrop on all their inner monologues — or if, like the lion, they frankly uttered to us everything that went through their minds (and Wittgenstein also notes that we have mastered their language) — even then, we'd still find them enigmatic. We can't find our feet with them. What then is the problem? What is this kind of understanding that eluded Wittgenstein in the case of Englishwomen? What would it consist in?

A remark quoted earlier gives us an idea of the kind of behaviour he has in mind that we would find incomprehensible:

So he gets angry, when we see no reason for it; what excites us leaves him unmoved. ... [LWI\$192]

Such unfamiliar reactions we don't understand. Is that because such anomalous reactions take us by surprise? That may be part of the problem (MS 173, 38v), but there is more to it. Wittgenstein continues as follows:

So he gets angry, when we see no reason for it; what excites us leaves him unmoved. - Is the essential difference that we can't foresee his reactions? Couldn't it be that after some experience we might know them, but still not be able to follow him? [LW I \$192] 
Even a good knowledge of the causal regularities that govern somebody's behaviour may not be enough for understanding. An amusing example of this is provided by the Monty Python 'Buying a bed' (1969). Trying to buy a bed in a department store, a young couple encounter some exceedingly eccentric sales assistants. Mr Lambert, for example, reacts to every utterance of the word 'mattress' by putting a bag over his head. When his colleagues stand in a tea chest and sing Jerusalem, he takes it off again. We are given to understand that this is a very regular and predictable series of event. So Mr Lambert's behaviour is not at all unpredictable, and yet, as Wittgenstein puts it, we are not able to follow him. This part of his behaviour remains utterly incomprehensible.

What more is required for understanding someone's behaviour? One obvious answer is: finding it reasonable. We understand people when we are able to rationalise their behaviour; when we see how what they do is sensible in the light of their aims. Failure to do so can be due to our own limitations. The reasons that guide someone's actions can be too complicated for the onlooker to understand (e.g., what people at the stock exchange do would remain incomprehensible to a child). Alternatively, some behaviour may not only appear unreasonable to an uninformed bystander, but just be unreasonable: whimsical, neurotic, or downright mad — like putting a bag over your head whenever you hear a certain word. Addiction provides more realistic examples. An alcoholic should stop drinking after the third glass, say, knowing full well that otherwise the consequences will be unpleasant, but is unable to control himself. Such behaviour is not understandable as reasonable intentional action; although, no doubt, we can investigate and come to understand the causal mechanisms that drive an alcoholic's behaviour. Understanding as discerning reasonable human behaviour is thwarted whenever somebody's behaviour, in the grip of a pathological condition, becomes unreasonable.

However, beside predictability and rationality there is yet a third aspect to understanding that Wittgenstein's considerations bring out. Those 1930s Englishwomen he was struggling to understand were presumably neither unpredictable nor outright irrational or akratic. They would not, like alcoholics, act contrary to their interests. They would not have certain aims, know how to achieve them, and yet fail to do so. What then would make them enigmatic to Wittgenstein?

We don't understand people if given their aims they do not take suitable steps to achieve them, or if they do what they know is not conducive to their well-being. That is irrationality, e.g. of compulsive behaviour. But we also fail to understand people who set 
themselves odd aims or have abnormal likes, preferences and inclinations. Such cases show that understanding people is not always a correlate of their rationality. Understanding people can also be a matter of familiarity or affinity and our ensuing ability to get on or feel at ease with them:

He is incomprehensible to me means that I cannot relate to him [mit ibm verkehren] as to others. [LWI\$198]

This is a concept of psychological understanding that goes beyond a purely intellectual achievement. You may be able to explain what motivates certain people and yet not be able to interact with them as with others, due to a difference in tastes or inclinations. Thus, people who do not share a similar sense of humour struggle to understand each other: 'They do not react properly to each other' ( $C V$ 95e). Suppose, my interlocutor makes a somewhat odd remark: slightly absurd, slightly bawdy. I may understand well enough that it is intended to be humorous, but if it doesn't strike a chord in me - if I just find it childish, insipid or offensive - I cannot play along in my reply. A certain kind of rapport proves impossible between us. In as much as I don't appreciate his sense of humour, I do not fully understand him ('How can he find that funny?!').

Consider again Wittgenstein's description of an incomprehensible person:

So he gets angry, when we see no reason for it; what excites us leaves him unmoved. ... [LWI I192]

Or, we may add, vice versa: what we find outragous leaves some people indifferent, and what they find wonderful strikes us as uninteresting. Anger can be an expression of moral indignation and it is easy to imagine such disagreements: what appears morally indifferent to some is shocking to others. Excitement can be an expression of aesthetic appreciation: and most artistic styles and their developments are exciting only to a relatively small group of connoisseurs, leaving most people unmoved.

This, in short, is an important observation implicit in Wittgenstein's remarks on psychological understanding, although one he merely touched upon without ever developing and explaining it in further detail. Understanding other people is not an entirely intellectual affair, but has also moral and aesthetic dimensions. To understand others can mean to be able to rationalize their behaviour: to see how given their aims it is reasonable. It can also mean to be able to foresee their responses, partly because of their rationality, but partly because we are sufficiently familiar with their dispositions. But in 
this latter case of familiarity with non-rational dispositions, we can speak of 'understanding' in a yet more demanding sense, namely: that we are able 'to follow' others in their dispositions. In this sense, 'I understand you' means not just: ' $I$ know that this is what you would do given your preferences and inclination', but more than that: 'I could imagine doing the same myself. Thus, to understand others in this emphatic sense (brought out by some of Wittgenstein's remarks) is not just an intellectual achievement, but requires some fundamental aesthetic and moral agreement. a sufficient affinity in one's tastes and attitudes. ${ }^{3}$

\section{Bibliography}

Baker, G.P. and Hacker, P.M.S. (1985), Wittgenstein: Rules, Grammar and Necessity: Vol 2 of an Analytical Commentary of the Philosophical Investigations (\$S 185-242), Oxford: Blackwell.

Bekoff, M. (2000), Animals Matter, Boston: Shambhala.

Glock, H-J. (1996), A Wittgenstein Dictionary, Oxford: Blackwell.

de Lara, Philippe (2005), L'expérience du langage: Wittgenstein philosophe de la subjectivité, Paris : Ellipses.

Locke, John (1690), An Essay Concerning Human Understanding, Oxford: OUP, 1979.

Sandis, Constantine (2012) 'Understanding the Lion For Real', in: A. Marques \& N. Venturinha (eds.), 2012. Knowledge, Language and Mind: Wittgenstein's Thought in Progress. Berlin: de Gruyter.

Schroeder, Severin (2006), Wittgenstein: The Way Out of the Fly-Bottle, Cambridge: Polity.

Schroeder, Severin (2017), 'Reasons and First-Person Authority', in: J. Padilla Gálvez \& M. Gaffal (eds), Intentionality and Action, Berlin: De Gruyter.

Wittgenstein, Ludwig:

CV: Culture and V alue. Revised Edition, ed.: G.H. von Wright, Oxford: Blackwell, 1998.

LW I: Last Writings on the Philosophy of Psychology Vol. 1, eds: .: G.H. von Wright \& H. Nyman, Oxford: Blackwell, 1982.

MS: Unpublished manuscript, numbered in accordance with G.H. von Wright's catalogue in: 'The Wittgenstein Papers', in his: Wittgenstein, Oxford: Blackwell, 1982.

PI: Philosophical Investigations. Fourth Edition. Edited by P. M. S. Hacker and Joachim Schulte. Translated by G. E. M. Anscombe, P. M. S. Hacker and Joachim Schulte. Oxford: Wiley-Blackwell, 2009.

PPF: 'Philosophy of Psychology — A Fragment', in: PI.

${ }^{3}$ I am grateful to Harry Tomany for his comments on this paper. 